\title{
Refractory Hypertension Leads to both Type A and B Aortic Dissections in a Single Patient
}

\author{
Anthony Lemaire*, Victoria G. Behrend, George Batsides, Aziz Ghaly, Al Solina, Alan Spotnitz and Leonard Y. Lee \\ RUTGERS-Robert Wood Johnson University Hospital, New Jersey, USA
}

Keywords: Aortic dissection; Hypertension; Refractory hypertension

\section{Introduction}

Hypertension is an important health challenge worldwide because of its high prevalence and concomitant increase in risk of disease [1]. It is the most important modifiable risk factor for cardiovascular, cerebrovascular, and renal disease [2]. Moreover, resistant hypertension (RHTN) is an increasingly common clinical problem that almost always has multiple etiologies, risk factors, and comorbidities [3,4]. The presence of RHTN and its association with increased cardiovascular risk has an impact on all patients specifically those patients who have undergone adult cardiac surgery. It has further been shown that hypertension is the major risk factor for patients who experience aortic dissection [5-8].

Aortic dissection is a medical emergency and can quickly lead to death, even with optimal treatment, as a result of decreased blood supply to other organs, cardiac failure, and sometimes rupture of the aorta. Aortic dissection is more common in those with a history of high blood pressure, and in a number of conditions that affect blood vessel wall integrity such as Marfan syndrome and the vascular subtype of Ehlers-Danlos syndrome. Furthermore, for patients who have previously developed aortic dissections, they are particularly at risk for further complications. In this case report we review a patient who developed both a Type A and B aortic dissection secondary to refractory hypertension.

\section{Case Report}

The patient is a 51 years African American male who developed a Type B aortic dissection in 2011. He had a history of hypertension that was difficult to control. The patient underwent an open repair of the type $\mathrm{B}$ aortic dissection because of uncontrollable pain and recovered well. After discharge from the hospital he was encouraged to continue with aggressive medical management of his blood pressure. Unfortunately, the patient failed to maintain normal blood pressure control and 3 years later he presented to the emergency room complaining of severe back and chest pain. On workup with a CT scan of the chest with contrast he was found to have a Type A aortic dissection (Figure 1). He was taken emergently to the operating room where he underwent repair. He tolerated the procedure and was ultimately sent home on strict monitoring of his blood pressure with a goal systolic blood pressure $<120 \mathrm{mmHg}$. This patient is one of the rare patients to experience and survive having both a Type A and B aortic dissection. The critical factor in this patient was his inability to control his blood pressure.

\section{Hypertension and Aortic Dissections}

Of the risk factors for developing Type A or Type B aortic dissections, chronic hypertension remains the most common predisposing factor and is present in $62-78 \%$ of patients presenting with aortic dissection [5-8]. One of the most comprehensive international studies on aortic dissections to date is comprised of case series on 464 patients and cites hypertension as present in $72.1 \%$ of patients with aortic dissection overall [8]. While chronic systemic hypertension appeared more prevalent in the population of patients with Type B dissections at $76.7 \%$ vs. those with Type A dissections at $69.3 \%$ there was no significant difference between the high proportion in these two groups $(\mathrm{p}=0.08)$ [8]. This contribution to aortic dissection is also remarkable in that the most affected demographic for either aortic dissection type is typically male $(65.3 \%)$ and Caucasian $(82.8 \%)$ with a mean age of $63.1 \pm 14$ years, with the rest of the patient population comprised of only1.7\% African American and $13.5 \%$ Asian patients [8]. In each circumstance, the most common presenting symptom was found to be abrupt onset of sharp pain of the utmost severity either in the anterior chest in Type A dissections $(\mathrm{p}<0.001)$ or back in Type B dissections $(\mathrm{p}<0.001)$, which this patient also experienced. Patients were also found to present with systolic hypertension on physical exam most commonly (49\%) with significantly more during a Type B vs [8]. Type A aortic dissection $(70.1 \%$ vs. $35.7 \%$ respectively, $\mathrm{p}<0.001)$, with Type A dissections presenting significantly more with new-onset murmur of aortic insufficiency $(44 \%, \mathrm{p}<0.001)$, pulse deficit $(18.7 \%, \mathrm{p}=0.006)$, and congestive heart failure $(8.8 \%, \mathrm{p}=0.02)$ [8]. The most common imaging modality used to detect aortic dissection was computed tomography (61.1\%) [8], which was used in the diagnosis of this patient (Figure 1).

Only $3.9 \%$ of patients with a Type A aortic dissection had experienced a previous unspecified type dissection versus $10.6 \%$ of patients with a Type B aortic dissection $(\mathrm{p}<0.005)$, making this

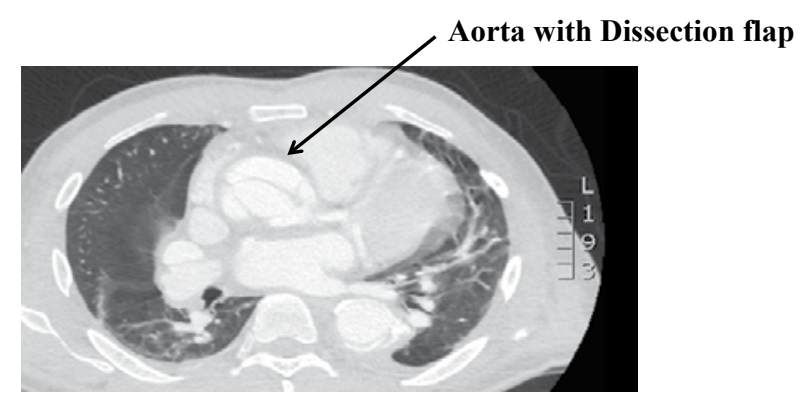

Figure 1: Axial CT image in the aforementioned 51 year old male patient demonstrating Type A aortic dissection s/p open repair of Type B aortic dissection three years prior. Separation of the intimal layer is evident by the dissection flap with intermediate blood extrusion between the intimal and medial layers of his vessel wall.

*Corresponding author: Anthony Lemaire, Assistant Professor, Division of Cardiothoracic Surgery, Department of Surgery, RUTGERS-Robert Wood Johnson University Hospital, 125 Paterson Street, New Brunswick, New Jersey, 08903, USA, Tel: 732-235-6171; Fax: 732-235-8727; E-mail: anthony.lemaire@rwjms.rutgers.edu

Received March 10, 2014; Accepted April 15, 2014; Published April 22, 2014

Citation: Lemaire A, Behrend VG, Batsides G, Ghaly A, Solina A, et al. (2014) Refractory Hypertension Leads to both Type A and B Aortic Dissections in a Single Patient. J Cardiovasc Dis Diagn 2: 155. doi:10.4172/2329-9517.1000155

Copyright: $\odot 2014$ Lemaire A, et al. This is an open-access article distributed under the terms of the Creative Commons Attribution License, which permits unrestricted use, distribution, and reproduction in any medium, provided the original author and source are credited. 
patient's case rare within the context of the International Registry of Acute Aortic Dissection database [8]. Further, in the rare published case reports of Type A then Type B aortic dissection or Type B then Type A aortic dissection in one patient, the dissections occurred within the same post-operative recovery period of up to 3 weeks and 12 days respectively $[9,10]$. This patient is unique in the current literature in that his dissection occurrences were separated by years after a full surgical recovery, during which time he was burdened with unremitting hypertension.

\section{Discussion}

The patient in this case report describes the significance of hypertension in the development of aortic dissection. This patient initially had a Type B aortic dissection but failed to control his blood pressure and developed a Type A aortic dissection. Multiple factors contribute to the development of aortic dissections however hypertension is a key factor. Refractory hypertension had been an increasing problem and can have devastating consequences. Critical to the management of hypertension is both pharmacologic and dietary changes.

The significance of hypertension to the development of aortic dissection cannot be understated. Acute aortic dissection is a challenging clinical emergency and it is the most common acute aortic condition requiring urgent surgical therapy. Prompt surgical therapy is the mainstay of treatment of Type A dissection and medical therapy is the primary treatment for Type B aortic dissection. The patient presented unfortunately had uncontrollable chest and back pain and was therefore treated surgically. This patient demonstrates the significance of hypertension to the development of aortic dissections both preoperatively and postoperatively. Taken together, the patient described should be an example of the key role in maintaining a stable blood pressure.

\section{References}

1. He J, Whelton PK (1997) Epidemiology and prevention of hypertension. Med Clin North Am 81: 1077-1097.

2. Ezzati M, Lopez AD, Rodgers A, Vander Hoorn S, Murray CJ; Comparative Risk Assessment Collaborating Group (2002) Selected major risk factors and global and regional burden of disease. Lancet 360: 1347-1360.

3. Lim SS, Vos T, Flaxman AD, Danaei G, Shibuya K, et al. (2012) A comparative risk assessment of burden of disease and injury attributable to 67 risk factors and risk factor clusters in 21 regions, 1990-2010: a systematic analysis for the Global Burden of Disease Study 2010. Lancet 380: 2224-2260.

4. Calhoun DA, Jones D, Textor S, Goff DC, Murphy TP, et al. (2008) Resistant hypertension: diagnosis, evaluation, and treatment: a scientific statement from the American Heart Association Professional Education Committee of the Council for High Blood Pressure Research. Circulation 117: e510-526.

5. Khan IA, Nair CK (2002) Clinical, diagnostic, and management perspectives of aortic dissection. Chest 122: 311-328.

6. Spittell PC, Spittell JA Jr, Joyce JW, Tajik AJ, Edwards WD, et al. (1993) Clinical features and differential diagnosis of aortic dissection: experience with 236 cases (1980 through 1990). Mayo ClinProc 68: 642-651.

7. Hennessy TG, Smith D, McCann HA, McCarthy C, Sugrue DD (1996) Thoracic aortic dissection or aneurysm: clinical presentation, diagnostic imaging and initial management in a tertiary referral center. Ir J Med Sci1 65:259-262.

8. Hagan PG, Nienaber CA, Isselbacher EM, Bruckman D, Karavite DJ, et al. (2000) The International Registry of Acute Aortic Dissection (IRAD): new insights into an old disease. JAMA 283: 897-903.

9. Gaur P, Kasirajan K, Miller DL, Vassiliades TA (2008) Hybrid Thoracic Sten Graft Repair of a Complex Type B Aortic Dissection in a Patient Who Presented Three Weeks After Repair of a Type A Aortic Dissection. Innovations 3:158160.

10. Rubin S, Bayle A, Poncet A, Baehrel B (2006) Retrograde aortic dissection after a stent graft repair of a type B dissection: how to improve the endovascular technique. Interact Cardiovasc Thorac Surg 5: 746-748. 